\title{
IMPLEMENTASI TEORI FUZZY TSUKAMOTO UNTUK MEMPREDIKSI TINGKAT KELULUSAN MAHASISWA INSTITUT AGAMA ISLAM NEGERI JEMBER
}

\author{
${ }^{1}$ Mega Nuris Salafinah, ${ }^{2} \mathrm{M}$ Zainul Arifin \\ ${ }^{1}$ Institut Agama Islam Negeri Jember \\ ${ }^{2}$ Institut Agama Islam Negeri Jember \\ e-mail : zainul220508@gmail.com
}

\begin{abstract}
Abstrak
Kelulusan merupakan suatu hal yang sangat diharapkan oleh setiap mahasiswa, yang nantinya akan menjadi bekal seorang mahasiswa dalam menempuh jenjang selanjutnya, untuk mencari pekerjaan, ataupun sebagai penunjang akreditasi bagi perguruan tinggi. permasalahnnya adalah apakah mahasiswa IAIN Jember bisa lulus dengan maksimal atau tidak. Dalam penelitian ini, lebih memfokuskan bagaimana implementasi teori fuzzy dalam memprediksi tingkat kelulusan mahasiswa IAIN Jember. Teori fuzzy banyak digunakan karena teori fuzzy memiliki beberapa kelebihan seperti mudah di mengerti, toleransi terhadap data yang kurang tepat. Pada penelitian ini menggunakan teori fuzzy tsukamoto dengan 3 variabel input yang terdiri dari jumlah penerimaan peserta wisuda, jumlah mahasiswa, dan jumlah mahasiswa yang lulus. Tujuan dari penelitian ini adalah untuk memprediksi jumlah mahasiswa yang lulus dalam setiap tahunnya di IAIN Jember.
\end{abstract}

Kata kunci: Logika fuzzy, metode tsukamoto, variabel input.

\section{PENDAHULUAN}

Dalam setiap institut setiap tahunnya pasti ada mahasiswa yang sudah lulus dan bergelar S1. Untuk setiap tahunnya mahasiswa yang lulus dapat mengalami penurunan atau mengalami peningkatan. Jika dilihat dari data peserta yang mengikuti wisuda dapat dikatakan bahwa setiap tahunnya mahasiswa yang lulus tidak pasti, terkadang mengalami penurunan atau terkadang mengalami peningkatan.

Untuk memprediksi jumlah mahasiswa yang lulus digunakan sebuah teori yaitu logika fuzzy, pada logika fuzzy terdapat beberapa metode yaitu metode tsukamoto, mamdani, dan sugeno. Dari ketiga metode tersebut terdapat perbedaan dan mempunyai karakterstik masingmasing. Namun pada artikel ini, peneliti lebih memfokuskan pada teori fuzzy metode tsukamoto.

Logika fuzzy diperkenalkan pertama kali oleh prof. Lutfi A. Zadeh, prof. Lutfi seorang peneliti dari Universitas California di Barkley dalam bidang ilmu computer pada tahun 1965 
(Rinaldi, 2016:80). Ia berpendapat bahwa logika benar atau salah tidak dapat mewakili pemikiran manusia, setelah itu dikembangkanlah logika fuzzy yang mampu mewakili pemikiran manusia.

Pada suatu teori himpunan fuzzy dikenal yang namanya derajat keanggotaan. Derajat keanggotaan merupakan anggota yang terdapat di dalam suatu elemen himpunan fuzzy. Nilai keanggotaan tersebut terletak di dalam selang [0-1]. Jika dalam suatu himpunan fuzzy derajat keanggotaannya kurang dari 0 atau lebih dari 1 , maka nilai tersebut tidak termasuk dalam derajat keanggotaan himpunan fuzzy.

Logika fuzzy banyak digunakan karena memiliki beberapa kelebihan yaitu teori ini mudah dipahami, mempunyai toleransi terhadap data yang tidak tepat, mampu mensistemkan fungsi-fungsi non linier yang sangat kompleks, mampu mengaplikasikan pengetahuan atau pengalaman dari para pakar, mampu bekerja sama dengan teknik-teknik secara konvensional, berdasarkan pada bahasa sehari-hari sehingga mudah dimengerti.

Logika fuzzy adalah salah satu pembentuk soft compoting. Dasar dari logika fuzzy adalah teori himpunan fuzzy (Siti, 2016:3). derajat keanggotaan memiliki peranan yang sangat penting yaitu sebagai penentu keberadaan suatu elemen dalam suatu himpunan. Dalam teori fuzzy dikenal yang namanya teori fuzzy metode tsukamoto. Metode tsukamoto merupakan metode yang mana untuk setiap konsekuen pada aturan IF-THEN harus di representasikan pada suatu himpunan fuzzy dengan fungsi keanggotaan yang monoton.

Pada penelitian sebeleumnya, metode tsukamoto digunakan untuk penentuan nilai reward yang diterima karyawan. Sistem inferensi pada metode tsukamoto dapat mengklarifikasi masalah pemberian reward yang diterima oleh karyawan. Sistem pendukung keputusan dengan menggunakan metode tsukamoto adalah menerapkan parameter atau variabel data pendukung yang meliputi jumlah penerimaan peserta wisuda, jumlah mahasiswa, dan jumlah mahasiswa yang lulus,

Pada metode tsukamoto setiap rule yang ada diterapkan dengan menggunakan himpunan fuzzy dengan fungsi keanggotaan yang konstan, teori fuzzy tsukamoto adalah metode yang memiliki toleransi pada data dan sangat fleksibel. Kelebihan metode tsukamoto adalah bersifat intuitif dan dapat memberikan tanggapan berdasarkan informasi yang bersifat kualitatif, tidak akurat, dan ambigu. 
Metode tsukamoto setiap aturan direpresentasikan menggunakan himpunan fuzzy, dengan fungsi keanggotaan yang bersifat monoton (Kristian,2018: 3). Setiap konsekuensi yang terdapat pada aturan yang berbentuk IF-THEN harus direpresentasikan dengan suatu himpunan fuzzy dengan fungsi keanggotaan yang monoton.

Pada kesempatan ini peneliti ingin menerapkan teori fuzzy untuk memprediksi jumlah lulusan mahasiswa IAIN Jember. Peneliti menggunakan metode tsukamoto dengan menggunakan perhitungan yang sistematis, sehingga diperoleh output nilai sebagai hasil dari perhitungan dari teori fuzzy metode tsukamoto.

\section{METODE PENELITIAN}

1. Metode penelitian

Metode yang digunakan dalam penelitian ini adalah metode fuzzy tsukamoto, dimana metode tsukamoto dalam penelitian ini digunakan unutk memprediksi kelulusan mahasiswa IAIN Jember.

2. Metode pengumpulan data

Proses pengumpulan data yang digunakan dalam penelitian ini melalui studi kepustakaan. Dimana, pengumpulan datanya dilakukan dengan mengambil bahan dari dokumentasi, literatur, jurnal, dan web IAIN Jember yang berhubungan dengan mahasiswa yang mengikuti wisuda. Sedangkan outputnya adalah dengan melihat jumlah mahasiswa yang lulus di IAIN Jember.

\section{HASIL DAN PEMBAHASAN}

Di dalam menentukan banyaknya mahasiswa yang lulus pada setiap tahunnya ada dua kriteria yang digunakan pada penelitian ini yaitu jumlah penerimaan mahasiswa wisuda dan jumlah mahasiswanya.

Tabel 1. Data jumlah penerimaan peserta wisuda, jumlah mahasiswa, jumlah yang lulus

\begin{tabular}{|l|l|l|}
\hline Variabel & Himpunan & Nilai fuzzy \\
\hline \multirow{2}{*}{$\begin{array}{l}\text { Jumlah penerimaan peserta } \\
\text { wisuda }\end{array}$} & Naik & $100-400$ \\
\cline { 2 - 2 } & Turun & \\
\hline Jumlah mahasiswa & Banyak & \\
\cline { 2 - 2 } & Sedikit & \\
\hline
\end{tabular}

Implementasi Teori Fuzzy Tsukamoto Untuk Memprediksi Tingkat Kelulusan Mahasiswa Institut 
Berapakah jumlah mahasiswa yang lulus jika diketahui:

Jumlah penerimaan $=300$

Jumlah mahasiswa $=1500$

Rule:

1. IF jumlah mahasiswa banyak dan jumlah penerimaan peserta wisuda naik THEN jumlah mahasiswa yang lulus bertambah

2. IF jumlah mahasiswa banyak dan jumlah penerimaan peserta wisuda turun THEN jumlah mahasiswa yang lulus berkurang

3. IF jumlah mahasiswa sedikit dan jumlah penerimaan peserta wisuda naik THEN jumlah mahasiswa yang lulus bertambah

4. IF jumlah mahasiswa sedikit dan jumlah penerimaan peserta wisuda turun THEN jumlah mahasiswa yang lulus berkurang

Penyelesaian menggunakan metode tsukamoto yaitu:

1. Memodelkan variabel fuzzy

a. Variabel penerimaan peserta wisuda

Variabel penerimaan peserta wisuda terdiri dari 2 himpunan yaitu naik dan turun. Untuk fungsi keanggotaan penerimaan peserta wisuda direpresentasikan sebagai berikut:

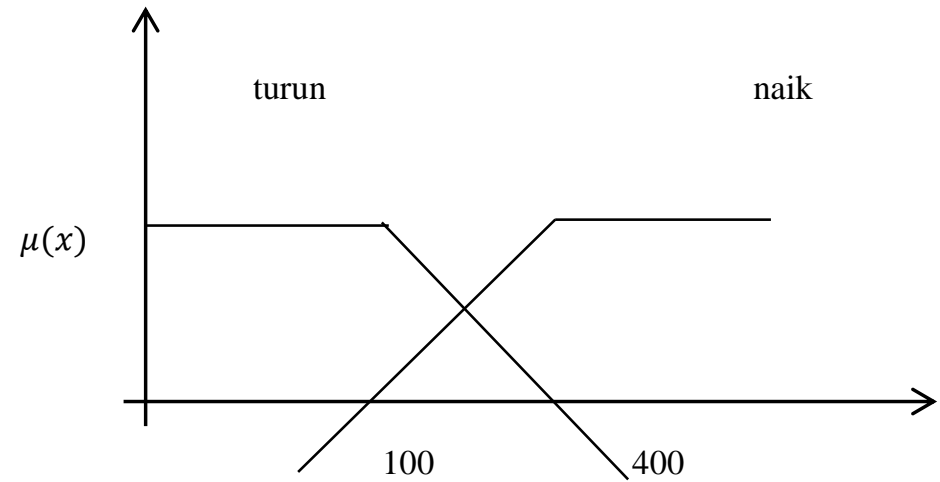


Grafik 2.1: Representasi kurva linier naik dan turun variabel x

Fungsi keanggotaan dari himpunan naik dan turun dari variabel jumlah penerimaan peserta wisuda adalah:

$$
\begin{aligned}
& \mu_{\text {turun }}(\mathrm{x}):\left\{\begin{array}{l}
0, \mathrm{x} \leq 100 \\
\frac{400-\mathrm{x}}{300}, 100 \leq \mathrm{x} \leq 400 \\
1, \mathrm{x} \geq 400
\end{array}\right. \\
& \mu_{\text {naik }}(\mathrm{x}):\left\{\begin{array}{l}
1, \mathrm{x} \leq 100 \\
\frac{\mathrm{x}-100}{300}, 100 \leq \mathrm{x} \leq 400 \\
0, \mathrm{x} \geq 400
\end{array}\right.
\end{aligned}
$$

Nilai keanggotaan himpunan naik dan turun dari variabel penerimaan peserta wisuda dapat diperoleh dengan cara sebagai berikut:

$$
\begin{aligned}
& \mu_{\text {pener turun }}(300)=\frac{400-300}{300} \\
& =\frac{100}{300} \\
& =0,34 \\
& \mu_{\text {pener naik }}(300)=\frac{300-100}{300} \\
& =\frac{200}{300} \\
& =0,66
\end{aligned}
$$

b. Fungsi keanggotaan variabel jumlah mahasiswa

Variabel jumlah mahasiswa terdiri dari 2 himpunan yaitu banyak dan sedikit. Grafik untuk fungsi keanggotaan jumlah mahasiswa sebagai berikut: 


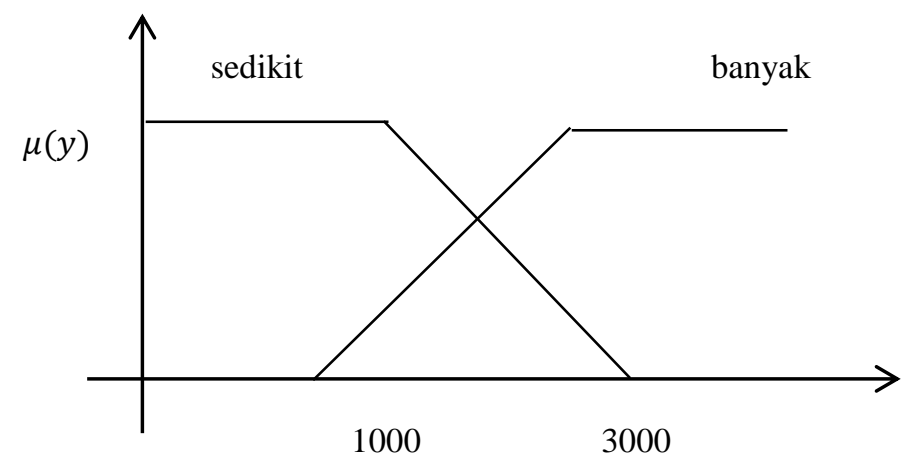

Grafik 2.2: Representasi kurva linier naik dan turun 27ariable y

Fungsi keanggotaan himpunan banyak dan sedikit dari variabel jumlah mahasiswa adalah:

$\mu_{\text {sedikit }}(\mathrm{y}):\left\{\begin{array}{c}0, \mathrm{y} \leq 1000 \\ \frac{3000-\mathrm{y}}{2000}, 1000 \leq \mathrm{y} \leq 3000 \\ 1, \mathrm{y} \geq 3000\end{array}\right.$

$\mu_{\text {banyak }}(\mathrm{y}):\left\{\begin{array}{l}1, \mathrm{y} \leq 1000 \\ \frac{\mathrm{y}-1000}{2000}, 1000 \leq \mathrm{y} \leq 3000 \\ 0, \mathrm{y} \geq 3000\end{array}\right.$

untuk nilai keanggotaan himpunan banyak dan sedikit dari variabel jumlah peserta dapat diperoleh dengan cara:

$\mu_{\text {pener banyak }}(1500)=\frac{3000-1500}{2000}$

$=\frac{1500}{2000}$

ARITMATIKA, Vol. 1, No. 1, Juni 2020. 
$=0,75$

$\mu_{\text {pener sedikit }}(1500)=\frac{1500-1000}{2000}$

$=\frac{500}{2000}$

$=0,25$

c. Fungsi keanggotaan variabel jumlah mahasiswa yang lulus

Variabel jumlah mahasiswa yang lulus terdiri dari 2 himpunan yaitu bertambah dan berkurang. untuk fungsi keanggotaannya direpresentasikan sebagai berikut;

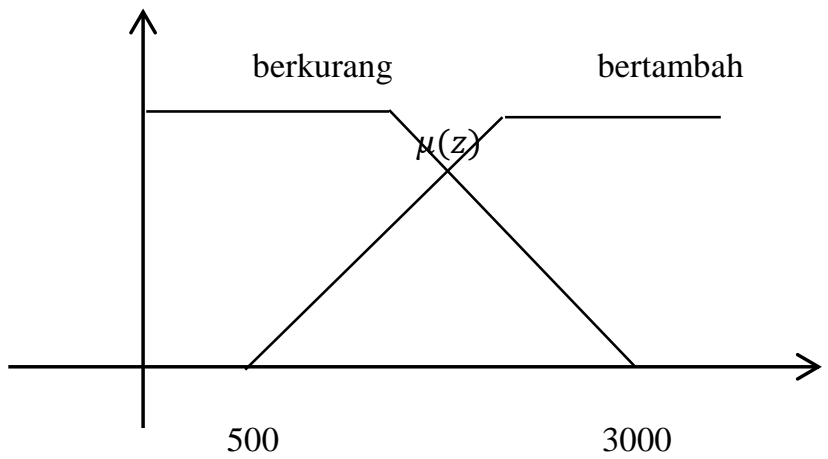

Grafik 2.3: Representasi kurva linier naik dan turun variabel z

Fungsi keanggotaan untuk himpunan bertambah dan berkurang dari variabel jumlah mahasiswa yang lulus adalah;

$$
\begin{aligned}
& \mu \text { berkurang }(\mathrm{z}):\left\{\begin{array}{l}
0, \mathrm{z} \leq 500 \\
\frac{3000-\mathrm{z}}{2500}, 500 \leq \mathrm{z} \leq 3000 \\
1, \mathrm{z} \geq 3000
\end{array}\right. \\
& \mu_{\text {bertambah }(\mathrm{z}):}\left\{\begin{array}{l}
1, \mathrm{z} \leq 500 \\
\frac{\mathrm{z}-500}{2500}, 500 \leq \mathrm{z} \leq 3000 \\
0, \mathrm{z} \geq 3000
\end{array}\right.
\end{aligned}
$$


Untuk mencari nilai keanggotaan himpunan bertambah dan berkurang dari variabel jumlah mahasiswa yang lulus, maka harus dicari nilai z nya terlebih dahulu dengan cara sebagai berikut:

Untuk mencari nilai z pada setiap aturan maka digunakan fungsi MIN pada aplikasi fungsi. Digunakanlah yang namanya aturan inferensi.

2. Aturan inferensi:

R1. IF jumlah mahasiswa banyak dan jumlah penerimaan peserta wisuda naik THEN jumlah mahasiswa yang lulus bertambah

$\alpha$-predikat $=\mu_{\mathrm{jlm} \text { mhsw banyak }} \bigcap_{\mathrm{jml} \text { pnrm psrta wisuda naik }}$

$=\min \left(\mu_{\mathrm{jml} \text { mhsw banyak }}[1500], \mu_{\text {pnrm psrta wisuda naik }}[300]\right)$

$=\min (0,75 ; 0,66)$

$=0,66$

Himpunan jumlah mahasiswa bertambah adalah

$\frac{z-500}{2500}=0,66$

$\mathrm{z}-500=1650$

$\mathrm{z}_{1}=1.150$

R2. IF jumlah mahasiswa banyak dan jumlah penerimaan peserta wisuda turun THEN jumlah mahasiswa yang lulus berkurang

$\alpha$-predikat $=\mu_{\mathrm{jlm} \text { mhsw banyak }} \bigcap_{\mathrm{jml} \text { pnrm psrta wisuda turun }}$

$=\min \left(\mu_{\text {jml mhsw banyak }}[1500], \mu_{\text {pnrm psrta wisuda turun }}[300]\right)$

$=\min (0,75 ; 0,34)$

$=0,34$

Himpunan jumlah mahasiswa berkurang adalah

$\frac{3000-\mathrm{z}}{2500}=0,34$

ARITMATIKA, Vol. 1, No. 1, Juni 2020. 
$3000-\mathrm{z}=850$

$\mathrm{z}_{2}=2150$

R3. IF jumlah mahasiswa sedikit dan jumlah penerimaan peserta wisuda naik THEN jumlah mahasiswa yang lulus bertambah

$\alpha$-predikat $=\mu_{\mathrm{jlm} \text { mhsw sedikit }} \bigcap_{\mathrm{jml} \text { pnrm psrta wisuda naik }}$

$=\min \left(\mu_{\mathrm{jml} \text { mhsw sedikit }}[1500], \mu_{\mathrm{pnrm} \text { psrta wisuda naik }}[300]\right)$

$=\min (0,25 ; 0,66)$

$=0,25$

Himpunan jumlah mahasiswa bertambah adalah

$\frac{\mathrm{z}-500}{2500}=0,25$

$z-500=625$

$\mathrm{z}_{3}=125$

R4. IF jumlah mahasiswa sedikit dan jumlah penerimaan peserta wisuda turun THEN jumlah mahasiswa yang lulus berkurang

$\alpha$-predikat $=\mu_{\text {jlm mhsw sedikit }} \bigcap_{\text {jml pnrm psrta wisuda turun }}$

$=\min \left(\mu_{\mathrm{jml} \text { mhsw sedikit }}[1500], \mu_{\mathrm{pnrm} \text { psrta wisuda turun }}[300]\right)$

$=\min (0,25 ; 0,34)$

$=0,25$

Himpunan jumlah mahasiswa berkurang adalah

$\frac{3000-\mathrm{z}}{2500}=0,25$

$3000-z=625$

$\mathrm{Z}_{4}=2375$ 
Setelah kita mencari nilai $\mathrm{z}$ pada masing-masing aturan inferensi, selanjutnya kita tentukan nilai output crisp.

3. Untuk menetukan output crisp digunakan rumus sebagai berikut:

$$
\begin{aligned}
& Z=\frac{(\alpha 1 \cdot z 1)+(\alpha 2 \cdot z 2)+(\alpha 3 \cdot z 3)+(\alpha 4 \cdot z 4)}{\alpha 1+\alpha 2+\alpha 3+\alpha 4} \\
& Z=\frac{0.66 \cdot 1150+0,34 \cdot 2150+0,25 \cdot 125+0,25 \cdot 2375}{0,66+0,34+0,25+0,25} \\
& Z=\frac{759+731+31,25+593,75}{1,5} \\
& Z=\frac{2115}{1,5} \\
& Z=1.410
\end{aligned}
$$

Jadi kesimpulannya untuk jumlah mahasiswa yang lulus setiap tahunnya sekitar 1.410 mahasiswa. dimana jumlah tersebut bisa dikatakan jumlah yang cukup banyak.

Pada tahap pertama yaitu memodelkan variabel fuzzy utuk mempernudah dalam perhitungan himpunan fuzzy. Pada tahap ini terdapat tiga variabel dimana pada setiap variabel tersebut direpresentasikan dengan bentuk grafik sesuai dengan aturan metode tsukamoto. Kemudian dihitung nilai keanggotaan dari setiap himpunan fuzzy tersebut dan nilai tersebut terletak di dalam selang [0,1]. Untuk tahap kedua yaitu tentang aturan inferensi, dimana aturan tersebut merupakan sebuah bentuk kerja perhitungan yang berdasar pada konsep teori himpunan fuzzy. Sesuai dengan definisi tersebut jika dilihat dari perhitungan inferensi diatas, yaitu sebuah perhitungan yang berdasar pada himpunan fuzzy yang sudah diperoleh sebelumnya.

Pada tahap yang terakhir yaitu menentukan output crisp untuk mengetahui nilai kebenaran dari operasi logika yang digunakan. Output crisp merupakan sebuah keputusan yang diperoleh dari hasil pengolahan logika. Dimana output crisp tersebut digunakan untuk mendapatkan keputusan tingkat kebenaran dari operasi logika yang digunakan. Sesuai dengan pernyataan tersebut diketahui bahwa jumlah penerimaan peserta wisuda yaitu sebanyak 300 dan jumlah tersebut 
termasuk pada kategori naik dan jumlah mahasiswa sebanyak 1500 dan masuk pada kategori banyak. Dari perhitungan output crisp diperoleh jumlah mahasiswa yang lulus yaitu sebanyak 1.410. sesuai dengan aturan inferensi bahwa ketika jumlah penerimaan peserta naik dan jumlah mahasiswa banyak maka tingkat kelulusan akan bertambah.

Pada penelitian sebelumnya, teori fuzzy digunakan oleh Zahra Cynthia. Teori fuzzy digunakan untuk memprediksi kelulusan siswa SMK. Jika melihat banyaknya peserta SNMPTN yang bukan hanya dari satu sekolah dan ditambah dengan penilaian masing-masing penyelenggara, maka hasil prediki menggunakan sistem teori fuzzy tidak menentukan secara pasti siswa yang lulus (Zahra, 2018:6). Jadi jika dilihat dari jumlah mahasiswa yang kuliah di IAIN Jember dan pada setiap tahun jumlahnya berbeda, maka hasil prediksi menggunakan sistem ini pun tidak menentukan secara pasti jumlah mahasiswa IAIN Jember yang dinyatakan lulus.

\section{KESIMPULAN}

Teori fuzzy tsukamoto dapat membantu dalam memprediksi jumlah mahasiswa yang lulus, meskipun sistem ini tidak menentukan secara pasti jumlah mahasiswa yang lulus, karena disesuaikan dengan jumlah mahasiswa dan jumlah penerimaan wisuda.

Untuk melihat jumlah mahasiswa yang lulus maka digunakanlah teori fuzzy tsukamoto. Pada metode tsukamoto dapat diselesaikan dengan beberapa tahap yaitu 1. Memodelkan variabel fuzzy, 2. Aturan inferensi, 3. Menentukan output crisp. Dengan kesimpulan mahasiswa yang lulus sekitar 1.410. dimana jumlah tersebut bisa dikatakan sudah cukup banyak.

\section{DAFTAR PUSTAKA}

\section{Books:}

Munir. Rinaldi. 2016. Matematika Diskrit. Bandung: Informatika Bandung. 


\section{Online journal:}

Abidah, Siti. 2016. Analisis Komparasi Metode tsukamoto Dan Sugeno Dalam Prediksi Jumlah Siswa Baru. Jurnal Bianglala Informatika. Diakses 27 april 2020 diambil dari https://scholar.google.co.id/scholar?hl=id\&as_sdt=0\%2C5\&q=Analisis Komparasi Metode Tsukamoto dan Sugeno dalam Prediksi Jumlah Siswa Baru $\underline{\& b \operatorname{tnG}}=$.

Adiguna, Mochamad A. Muhajirin, Adi. 2017. Penerapan Logika Fuzzy Pada Penilaian Mutu Dosen Terhadap Tri Dharma Perguruan Tinggi: (JOIN Vol 2 No 1) 16-19. Diakses $25 \quad$ april 2020 diambil dari https://scholar.google.co.id/scholar?hl=id\&as_sdt=0\%2C5\&q=penerapan logika fuzzy pada penilaian mutu dosen terhadap tri dharma perguruan tinggi \&btnG $=$.

Kristian, R Ananda. Wahyuni, Ida. 2018. Penentuan Topik Judul Tugas Akhir Mahasiswa Di STMIK Asia malang Menggunakan Fuzzy Inference System Tsukamoto. Jurnal Ilmiah Teknologi Informasi Asia. Diakses 10 mei 2020 diambil dari https://scholar.google.co.id/scholar?hl=id\&as_sdt=0\%2C5\&q=Penentuan $\quad$ Topik Judul Tugas Akhir Mahasiswa di STMIK Asia Malang Menggunakan Fuzzy Inference System Tsukamoto \&btnG $=$.

Rijal, Yusron. Abdulla. Sistem pendukung Keputussan Kelulusan Nilai SK-Emas STMIK Yadika Menggunakan Metode Logika Fuzzy: (Smatika Vol 7 No 2) 6 - 13. Diakses 27 april 2020 diambil dari https://scholar.google.co.id/scholar?hl=id\&as_sdt=0\%2C5\&q=Sistem Pendukung Keputusan Kelulusan Nilai Sk-Emas STMIK Yadika Menggunakan Metode Logika Fuzzy \&btnG $=$.

Riyadi, Firman A. Avianto, Donny. 2020. Implementasi Metode Nä̈ve Bayes Untuk Memprediksi Kelulusan Mahasiswa Tepak Waktu Prodi Informatikai. Universitas Teknologi Yogyakarta: 2-8. Diakses 10 mei 2020 diambil dari https://scholar.google.co.id/scholar?hl=id\&as_sdt=0\%2C5\&q=NASKAH PUBLIKASI IMPLEMENTASI METODE NAÏVE BAYES UNTUK 


$\begin{array}{llllll}\text { PREDIKSI KELULUSAN } & \text { MAHASISWA } & \text { TEPAT } & \text { WAKTU } & \text { PRODI }\end{array}$

INFORMATIKA \&btnG $=$.

Rohmawan, Eko Prasetyo.2018. Prediksi Kelulusan Mahasiswa Tepak Waktu Menggunakan Metode Decision Tree Dan Articial Neural Network. Jurnal ilmiah. Diakses 16 april 2020 diambil

dari

http://scholar.google.co.id/scholar?hl=id\&as_sdt=0\%2C5\&q=PREDIKSI

KELULUSAN MAHASISWA TEPAT WAKTU MENGGUNAKAN

METODE DECISION TREE DAN ARTIFICAL NEURAL

NEKWORK \&btnG $=$.

Setywidodo, Irwan. Hariri, Fajar R. 2017. Implementasi Metode Fuzzy Tsukamoto Untuk Prediksi Hasil Panen Padi. Simki-Techsain. Diakses 27 april 2020 diambil dari https://scholar.google.co.id/scholar?hl=id\&as_sdt=0\%2C5\&q=implementasi metode fuzzy tsukamoto untuk prediksi hasil panen padi \&btnG $=$.

Welim, Yohannes Y. Wisjhnuadji, T.W. 2013. Pengaruh Implikasi Dan Motivasi Dalam Memprediksi Ketetapan Waktu Kelulusan Mahasiswa Dengan Menggunakan Sistem Pakar Berbasis Adaptive Neuro Fuzzy. Seminar Nasional Sistem Informasi Indonesia. $\begin{array}{llll}\text { Diambil } & 16 & \text { april } & 2020\end{array}$ http://scholar.google.co.id/scholar?hl=id\&as_sdt=0\%2C5\&q=PENGARUH IPK DAN MOTIVASI DALAM MEMPREDIKSI KETETAPAN WAKTU KELULUSAN MAHASISWA DENGAN MENGGUNAKAN SISTEM PAKAR BERBASIS ADAPTIVE NEURO FUZZY\&btnG $=$.

\section{Theses, Dissertation:}

Ayuningtias, Laras P. Irfan, Mohammad. 2017. Analisis Perbandingan Logic Fuzzy Metode Tsukamoto, Sugeno, Dan Mamdani (Studi Kasus: Prediksi Jumlah Pendaftar Mahasiswa Baru fakultas Sains Dan teknologi Universitas Islam Negeri Sunan Gunung Jati Bandung). Jurnal Teknik Informatika. Diakses 22 april 2020 diambil dari http://scholar.google.co.id/scholar?hl=id\&as_sdt=0\%2C5\&q=PERBANDINGAN $\begin{array}{llllll}\text { LOGIC } & \text { FUZZY } & \text { METODE } & \text { TSUKAMOTO\%2C } & \text { SUGENO\%2C } & \text { DAN }\end{array}$

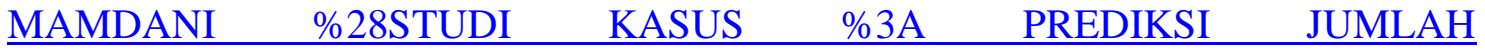
$\begin{array}{lllll}\text { PENDAFTAR } & \text { MAHASISWA } & \text { BARU } & \text { FAKULTAS } & \text { SAINS }\end{array}$ 
TEKNOLOGI UNIVERSITAS ISLAM NEGERI SUNAN GUNUNG DJATI BANDUNG\%29 \&btnG $=$.

Dewi, Zahra C. Nursikuwagus, Agus. 2018. Analisis Prediksi Kelulusan Siswa SMK pada SNMPTN Menggunakan Metode Fuzzy Mamdani (Studi Kasus: SMK Negeri 4 Bandung): 1- 6. Diakses 27 april 2020 diambil dari https://scholar.google.co.id/scholar?hl=id\&as_sdt=0\%2C5\&q=Analisis Prediksi Kelulusan Siswa SMK pada SNMPTN Menggunakan Metode Fuzzy

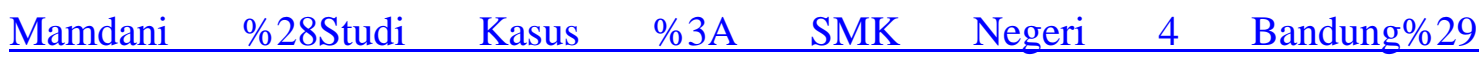
$\underline{\& b t n G}=$. 